\title{
Tn7 transposition: two transposition pathways directed by five Tn7-encoded genes
}

\author{
Candace S. Waddell ${ }^{1,3}$ and Nancy L. Craig ${ }^{1-3}$ \\ ${ }^{1}$ Department of Biochemistry and Biophysics, ${ }^{2}$ Department of Microbiology and Immunology, and the ${ }^{3}$ G.W. Hooper \\ Foundation, University of California at San Francisco, San Francisco, California 94143-0552 USA
}

\begin{abstract}
The bacterial transposon Tn7 is capable of high-frequency transposition to a specific site in the Escherichia coli chromosome, attTn 7 , and of low-frequency transposition to sites other than att Tn 7 . Using an in vitro insertional mutagenesis procedure, we have identified and characterized five $t$ (ns ( $T n$ seven) genes that are essential for $\mathrm{Tn} 7 \mathrm{transposition}$. Three of these genes, $\operatorname{tns} A, \operatorname{tns} B$, and $\operatorname{tns} C$, are required, but are not sufficient, for all $\mathrm{Tn} 7$ transposition events. In addition, $\operatorname{tns} D$ is specifically required for transposition to att $T n 7$, whereas tnsE is specifically required for transposition to other sites. Thus, $\mathrm{Tn} 7$ is an elaborate transposon that encodes two distinct but overlapping transposition pathways.
\end{abstract}

[Key Words: $\mathrm{Tn} 7$; transposition; recombination; in vitro mutagenesis]

Received October 22, 1987; revised version accepted December 21, 1987.

Transposons are DNA segments that have the capacity to move from one position to another within a genome. They encode proteins, generally one or two, that are required for transposition and cis-acting DNA sequences, often inverted repeats, that define their termini (for review, see Kleckner 1981; Shapiro 1983; Grindley and Reed 1985). Many bacterial transposons also encode other genetic determinants such as antibiotic resistances. Most transposable elements transpose to many different sites within a genome and, thus, can occasionally insert into genes essential to their host. Perhaps to minimize this deleterious event, transposition for most elements is a low-frequency, tightly regulated event.

The transposon $\operatorname{Tn} 7$ (Barth et al. 1976), which encodes resistance to trimethoprim and to spectinomycin and streptomycin, is remarkable in that it transposes at high frequency to a specific chromosomal site in many different bacteria (Hernalsteens et al. 1980; Thomson et al. 1981; Ely 1982). In Escherichia coli, where Tn7 transposition has been studied most extensively, this site, called $\operatorname{att} T n 7$, is located at minute 84 of the chromosome (Barth et al. 1976; Lichtenstein and Brenner 1981, 1982; Walker et al. 1984). The specific point of Tn7 insertion lies within the transcription terminator of $\operatorname{glm} S$ (Gay et al. 1986; E. Gringauz, K. Orle, C. Waddell, and N. Craig, in prep.), a gene involved in cell-wall biosynthesis. Because Tn7 insertions in att $T n 7$ do not physically disrupt the glmS-coding region, high-frequency transposition to this site can be tolerated by the cell. Chromosomal DNA segments containing att $T n 7$ also serve as targets for high-frequency, site-specific Tn7 transposition when they are introduced into plasmids (Lichtenstein and Brenner 1981; Rogers et al. 1986;
McKown et al. 1988). The ends of $\mathrm{Tn} 7$ show no sequence homology to attTn7 (Lichtenstein and Brenner 1982; Gay et al. 1986; McKown et al. 1988; E. Gringauz, K. Orle, C. Waddell, and N. Craig, in prep.|. Tn7 also transposes at low frequency into many different sites in plasmids (Barth and Grinter 1977; Barth et al. 1978).

In early experiments to identify the transposition genes encoded by $\operatorname{Tn} 7$, several groups examined the effect of internal deletions of $\mathrm{Tn} 7$ on transposition (Hauer and Shapiro 1984; Smith and Jones 1984; Ouartsi et al. 1985). These studies clearly established that (1) all required transposition genes are encoded within a $9-\mathrm{kb}$ region of the 14-kb $\operatorname{Tn} 7$ transposon (2) at least three separate genes are encoded within this region, and (3) Tn7 transposition proteins, unlike those of many IS elements (e.g., Isberg and Syvanen 1981; Morisato et al. 1983), complement efficiently in trans. Hauer and Shapiro (1984) demonstrated that one of the transposition genes is dispensable for transposition from plasmids to the chromosomal att $\operatorname{Tn} 7$ site.

We chose to define the transposition genes of $\operatorname{Tn} 7$ by insertional mutagenesis, an approach that allows finer dissection of a region than does deletion analysis. Our studies revealed a surprisingly complex array of genes. We have identified five ths (Tn seven) transposition genes and two distinct but overlapping pathways for $\operatorname{Tn} 7$ transposition. $\operatorname{tns} A, \operatorname{tn} s B$, and $\operatorname{tn} s C$ are required for all transposition events but are unable to promote transposition in the absence of tns $D$ or tnsE. High-frequency transposition to att $T n 7$ is promoted by $\operatorname{tn} s A B C+\operatorname{tn} s D$, whereas low-frequency transposition to sites other than att $\operatorname{Tn} 7$ is promoted by tns $A B C+\operatorname{tns} E$. Thus, tns $D$ and tnsE determine the transposition pathway used by $\operatorname{Tn} 7$. 
Concurrent with our own studies, Rogers et al. (1986) also identified tnsA-tnsE using complementation tests between a collection of $\mathrm{Tn} 7$ restriction fragments. The tns designation was agreed upon by our two groups because it does not imply mechanism or function. It is not clear which tns gene, or genes, encodes the enzymatic activity commonly associated with 'transposases'; i.e., the precise joining of the transposon's ends to target DNA sequences.

\section{Results}

\section{Characterization of the tns plasmid pCW4}

We have developed a transposition system consisting of three components: (1) a plasmid, pCW4, containing the Tn7 transposition genes, (2) a transposition-defective $\mathrm{Tn} 7$ derivative containing the ends of $\operatorname{Tn} 7$, and (3) a conjugable plasmid that serves as the target for transposition. pCW4 contains the rightward $9 \mathrm{~kb}$ of $\operatorname{Tn} 7$ and 165 bp of flanking att $T n 7$ sequence inserted into the small, multicopy vector pACYC184 (Chang and Cohen 1978). The Tn7 fragment in pCW4 is itself unable to transpose because it does not contain both left and right end sequences of $\operatorname{Tn} 7$. pCW4 was assayed for its ability to promote the transposition of a Tn7-end derivative in trans. One of two such end derivatives was used: miniTn7Cm (Hauer and Shapiro 1984) or miniTn7Km (L. Arciszewska and N. Craig, in prep.). Both derivatives contain all the essential cis-acting sequences at their termini required for transposition and lack any intact transposition gene. Transposition of a Tn7-end derivative from the chromosomal att $T n 7$ site to a conjugable plasmid was determined by a mating-out assay. One of two conjugable plasmids was used as the target for transposition: (1) pOX38-Gen, attTn7 (L. Arciszewska and N. Craig, in prep.), hereafter referred to as pOX-attTn7, to evaluate transposition to $\operatorname{att} T n 7$, or (2) pOX38-Gen (Johnson and Reznikoff 1984), hereafter referred to as pOX, to examine transposition to other sites.

As shown in Table 1, transposition of a Tn7-end element to both target plasmids is dependent on pCW4 (lines 2 and 3). In the presence of pCW4, the Tn7-end element transposes at approximately the same frequency as does intact $\operatorname{Tn} 7$ (compare lines 1 and 2). Transposition to pOX-att $T n 7$ occurs at a frequency approximately 50 - to 75 -fold higher than to pOX (lines 1 and 2), demonstrating the activity of att $\operatorname{Tn} 7$. Thus, the Tn7 transposition genes in pCW4 and a Tn7-end element in trans mimic transposition of intact $\mathrm{Tn} 7$.

To further characterize pCW4-promoted transposition events, products from transpositions to both pOXattn $\operatorname{Tn} 7$ and pOX were analyzed physically to determine the distribution of insertions within the target plasmids. All transpositions to pOX-att $T n 7$ occurred into the same restriction fragment (Fig. 1, lanes 1-4), consistent with site-specific transposition to att $T n 7$. In contrast, transpositions to pOX occurred into several different restriction fragments (Fig. 1, lanes 5-8), indicating low specificity of insertion. These results, together with the data in Table 1, demonstrate that pCW4 contains all the
Table 1. Tn7 and pCW4-promoted transposition

\begin{tabular}{|c|c|c|c|}
\hline \multirow[b]{2}{*}{ Tn7 element } & \multirow[b]{2}{*}{ Plasmid } & \multicolumn{2}{|c|}{ Target plasmid ${ }^{\mathrm{a}}$} \\
\hline & & pOX & pOX-att $T n 7$ \\
\hline $\begin{array}{l}\operatorname{Tn} 7^{b} \\
\operatorname{mini} \operatorname{Tn} 7 \mathrm{Cm}^{\mathrm{c}} \\
\operatorname{mini} \operatorname{Tn} 7 \mathrm{Cm}^{\mathrm{d}}\end{array}$ & $\begin{array}{l}-\bar{c} \\
\text { pCW4 } \\
\text { pACYC184 }\end{array}$ & $\begin{array}{r}1.7 \times 10^{-4} \\
1.5 \times 10^{-4} \\
<2.2 \times 10^{-8}\end{array}$ & $\begin{array}{r}9.4 \times 10^{-3} \\
1.1 \times 10^{-2} \\
<7.2 \times 10^{-9}\end{array}$ \\
\hline
\end{tabular}

a Transposition frequencies of Tn7 element from the chromosomal att $T n 7$ site were determined by a mating-out assay. Plasmids are as indicated. Each number is the average of three to nine independent trials.

b Numbers from L. Arciszewska and N. Craig (in prep.).

c Transposition frequencies of miniTn $7 \mathrm{Cm}$ were approximately the same when the Tn7 fragment in pCW4 was inserted in the opposite orientation (data not shown).

$\mathrm{d}$ pOX-att $T n 7$ number is the transposition frequency of mini$\operatorname{Tn} 7 \mathrm{Km}$.

Tn7-encoded genes required to promote both high-frequency transposition to att $T n 7$ and low-frequency transposition to other sites.

\section{Mutagenesis of $p C W 4$}

To identify the Tn7-encoded genes involved in transposition, pCW4 was subjected to insertional mutagenesis with a miniMu transposon. The element, miniMu $\Omega$, consists of $\Omega$ (Prentki and Krisch 1984), a spectinomycin/streptomycin-resistance determinant flanked by transcription and translation termination signals, bounded by the left and right ends of $\mathrm{Mu}$. MiniMu $\Omega$ insertions in pCW4 were generated by an in vitro reaction in which pCW4 served as the target for miniMu $\Omega$ transposition (see Materials and methods for details) and were recovered by transformation into a strain that lacked a Tn7-end element. This precaution was taken to allow recovery of mutations that might have been lethal to a host containing a Tn7-end element.

We have characterized 96 simple insertions of mini$\mathrm{Mu} \Omega$ in $\mathrm{pCW} 4$ generated by this procedure. Figure 2 shows the map position and orientation of each of these $96 \mathrm{miniMu} \Omega$ insertions as determined by restriction enzyme analysis. Eighteen insertions map in nonessential regions of pACYCl84 or in attTn7, whereas 78 insertions map within the $\mathrm{Tn} 7$ fragment. It is interesting to note the distribution of miniMu $\Omega$ insertions within the Tn7 sequences. Although miniMu $\Omega$ insertions map throughout the fragment, two regions--between positions 1.7 and $3.5 \mathrm{~kb}$ and between positions 6.45 and 7.8 $\mathrm{kb}-$ - are notably barren. It is tempting to speculate that the paucity of miniMu $\Omega$ insertions within these regions reflects properties of the disrupted tns genes. Perhaps the majority of insertions in these regions result in the production of truncated Tns polypeptides, lethal to the host. However, it is also possible that the distribution of miniMu $\Omega$ insertions reflects features of $\mathrm{Mu}$ transposition (Raibaud et al. 1979; Kamp and Kahmann 1981; M. Mizuuchi and K. Mizuuchi, pers. comm.). 


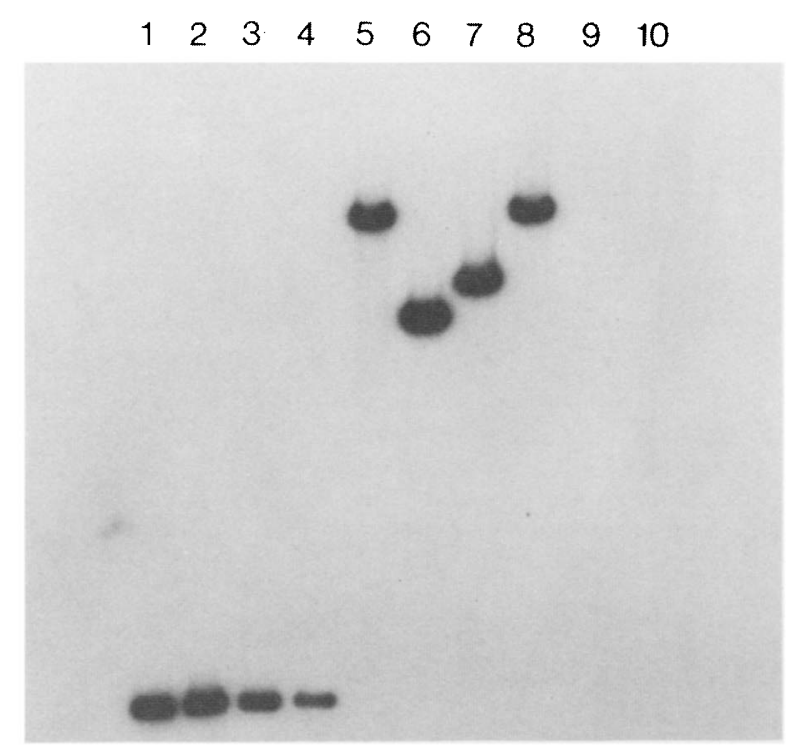

Figure 1. DNA analysis of pCW4-promoted transposition products. Products are from mating-out assays in which miniTn $7 \mathrm{Km}$ transposed from the chromosomal att $T n 7$ site to pOX or to pOX-attTn7. Each lane is a single transposition product from an independent mating-out experiment. Total DNA was prepared from exconjugants that had acquired $\mathrm{Km}^{\mathrm{R}}$. The DNA was digested with EcoRI, size-separated by electrophoresis, and probed with the nick-translated kanamycin fragment of miniTn $7 \mathrm{Km}$. EcoRI digestion of pOX $(59.4 \mathrm{~kb}$ in size $)$ yields seven fragments ranging in size from 23.0 to $0.2 \mathrm{~kb}$; there is no EcoRI cleavage site within miniTn $7 \mathrm{Km}(1.8 \mathrm{~kb}$ in size). Therefore, this analysis is limited to determining the EcoRI restriction fragment of pOX into which miniTn $7 \mathrm{Km}$ transposed. The predicted sizes of mini $T n 7 \mathrm{Km}$-containing fragments are $24.8,16.0,13.1,10.4,3.1,2.6$, and $2.0 \mathrm{~kb}$. Bands of approximately $25.5,17.0,14.5$, and $11.0 \mathrm{~kb}$ were observed. Insertions into the three smallest fragments, which represent approximately $4 \%$ of the target plasmid, were not observed. pOX$a t t \operatorname{Tn} 7$ has an additional EcoRI site within the att $\operatorname{Tn} 7$ cassette; a novel $4.5-\mathrm{kb}$ band was observed in transposition products to pOX-attTn7. The tns and target plasmids are as indicated. (Lanes 1-4) pCW4/pOX-attTn7; (lanes 5-8) pCW4/pOX. No hybridization to pOX-attTn7 (lane 9) or to pOX (lane 10) was observed in the absence of a miniTn $7 \mathrm{Km}$ insertion.

\section{Analysis of $p C W 4::$ miniMu $\Omega$ derivatives}

Eighty-four of the pCW4 :: miniMu $\Omega$ plasmids were introduced into strains containing a Tn7-end element by transformation. These plasmids represent most of the insertions mapping within $\operatorname{Tn} 7$ and $\operatorname{att} \operatorname{Tn} 7$ sequences and three insertions mapping within pACYC184 sequences. With all $84 \mathrm{pCW} 4::$ miniMu $\Omega$ plasmids, transformants were recovered that had no detectable growth defects. Therefore, none of the miniMu $\Omega$ insertions produced mutations conditionally lethal for Tn7-bearing strains. The capacity of each plasmid to promote transposition to pOX and to pOX-attTn7 was determined by a mating-out assay and evaluated qualitatively. A quantitative determination of the transposition frequency was also performed for a subset of the plasmids.

As expected, miniMu $\Omega$ insertions in $\mathrm{pACYCl} 84$ and in attTn7 sequences had little or no effect on miniTn $7 \mathrm{Cm}$ transposition (Fig. 2). Plasmids containing these insertions promoted miniTn7Cm transposition to pOX and to pOX-att $\operatorname{Tn} 7$ at an average frequency of $6.5 \times 10^{-5}$ and $2.8 \times 10^{-2}$, respectively. We also observed that miniMu $\Omega$ insertions in $\mathrm{Tn} 7$ sequences between positions 7.85 and $8.7 \mathrm{~kb}$ (Fig. 2) had no effect on the ability of pCW4 to promote transposition /average transposition frequency to pOX, $9.5 \times 10^{-5}$; to pOX-att $\left.\operatorname{Tn} 7,4.7 \times 10^{-2}\right)$. Thus, this region of $\operatorname{Tn} 7$ has no detectable role in transposition.

In sharp contrast, all other pCW4 derivatives with miniMu $\Omega$ insertions in $\operatorname{Tn} 7$ sequences between positions 0.1 and $7.8 \mathrm{~kb}$ (Fig. 2) were altered in their capacity to promote transposition. These plasmids exhibited one of three distinct mutant phenotypes. One class was defective in transposition to both pOX and pOX-attTn7, another was altered only in transposition to pOX, and the third was specifically altered in transposition to pOX-att $T n 7$.

All miniMu $\Omega$ insertions between positions 0.1 and 4.7 kb (Fig. 2) eliminated transposition of miniTn7Cm to both pOX and pOX-attTn 7. Transposition of miniTn7Cm was undetectable in the presence of these mutant plasmids $-<1.0 \times 10^{-7}$ and $<79.0 \times 10^{-8}$ to pOX and to pOX-att $T n 7$, respectively. Thus, this region encodes proteins required for all $\operatorname{Tn} 7$ transposition events. Further analysis of this region has revealed that it encodes three tns genes: $\operatorname{tns} A, \operatorname{tns} B$, and tns $C$ (see below).

Plasmids with miniMu $\Omega$ insertions between positions 6.2 and $7.8 \mathrm{~kb}$ (Fig. 2) were altered only in transposition to pOX and define the transposition gene tnsE. In the presence of these plasmids, miniTn7Cm transposition to pOX was undetectable (average transposition frequency $<1.8 \times 10^{-7}$ ), but transposition to pOX-att Tn 7 occurred at high, wild-type frequencies (average transposition frequency, $\left.4.5 \times 10^{-2}\right)$. These results suggest that the tnsE gene product is specifically required for transposition to sites other than att $T n 7$ and that all transposition events promoted by these tnsE mutants occur to att $T n 7$. We physically examined transposition products to pOX-attTn7 promoted by a tnsE mutant and found that all insertions occurred into the restriction fragment unique to that target (Fig. 3, lanes 13-16, lane 17), consistent with site-specific transposition to $\operatorname{att} \operatorname{Tn} 7$. Thus, tnsE mutations have no effect on transposition to att $\operatorname{Tn} 7$.

Two lines of evidence suggest that all insertions with the TnsE mutant phenotype identify a single gene: (1) A single polypeptide is encoded by this region whose molecular weight is consistent with the coding capacity of the region (Brevet et al. 1985; Smith and Jones 1986; C. Waddell and N. Craig, unpubl.) and (2) DNA sequence analysis has revealed one open reading frame (ORF) within this region (Smith and Jones 1986) with its amino terminus near position $6.2 \mathrm{~kb}$.

Plasmids with miniMu $\Omega$ insertions between positions 5.0 and $6.05 \mathrm{~kb}$ (Fig. 2) were specifically altered in transposition to pOX-att $\operatorname{Tn} 7$ and define the transposition gene tns $D$. In the presence of these $\mathrm{pCW} 4$ derivatives, miniTn7Cm transposition to pOX-att $T n 7$ was reduced approximately 50 -fold, as compared to wild-type trans- 

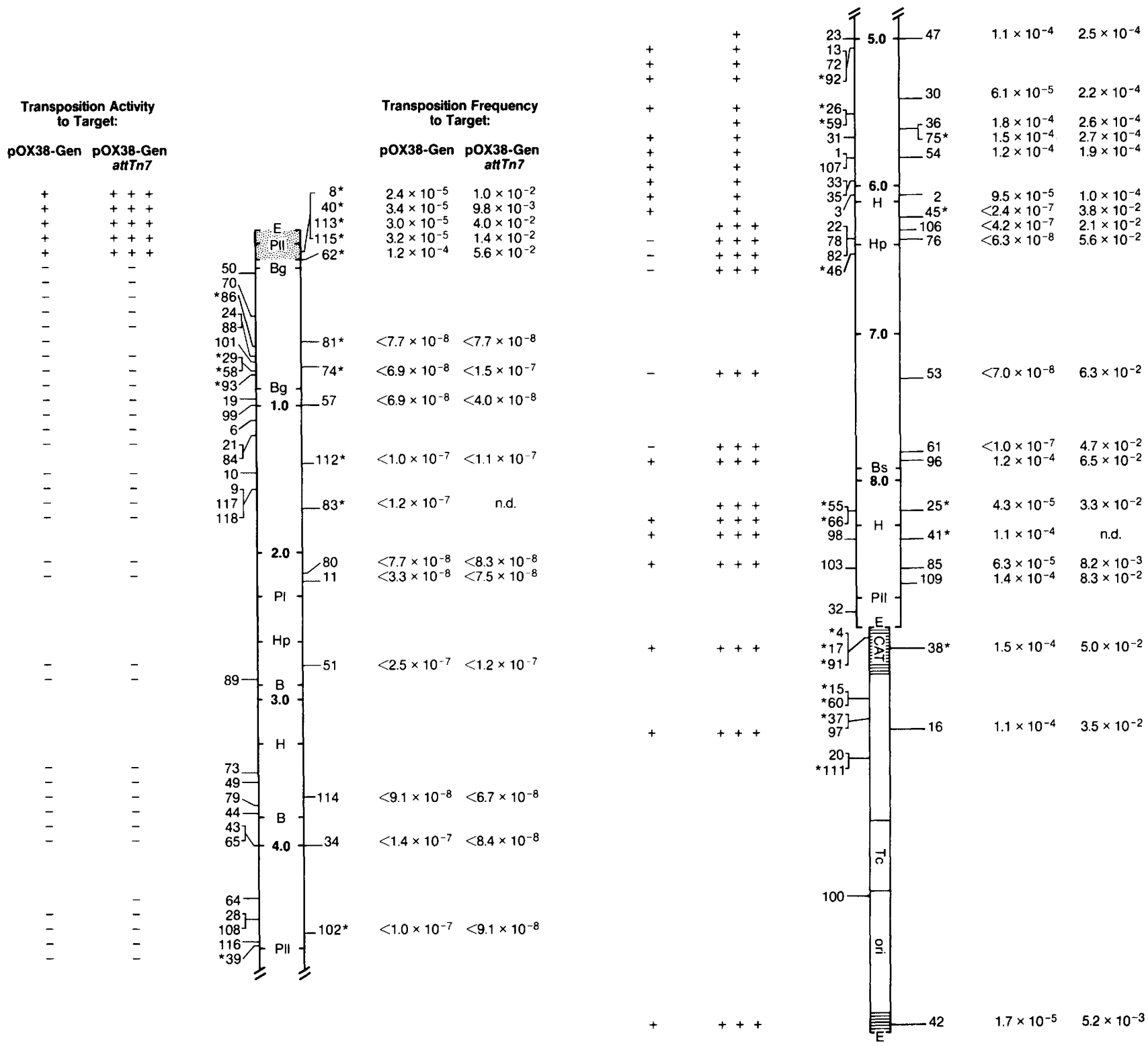

Figure 2. miniMu $\Omega$ insertions in pCW4. The wide vertical box represents the $\operatorname{Tn} 7$ (open) and att $\operatorname{Tn} 7$ (speckled) sequences in pCW4. Boldface numbers within the box indicate the length of $\mathrm{Tn} 7$ sequences in $\mathrm{kb}$. Letters indicate sites cleaved by restriction enzymes. (B) BamHI; (Bg) BglII; (Bs) BstEII; (E) EcoRI; (H) HindIII; (Hp) HpaI; (PI) PvuI; (PII) PvuII. The narrow vertical box represents the pACYC184 sequences of pCW4. This region is drawn at two-thirds the scale of the Tn7 sequences. The total length of pACYC184 is $4.0 \mathrm{~kb}$ () The disrupted chloramphenicol acetyltransferase gene (CAT); the tetracycline resistance gene (Tc) and the origin of replication (ori) are also indicated. No restriction sites in pACYCl84 sequences are shown. Ninety-six independent miniMu $\Omega$ insertions into pCW4 were obtained, as described in the text and in Materials and methods. Each insertion is identified by a number, and its map position is indicated by a horizontal line adjacent to its number. The positions of several insertions were indistinguishable by restriction enzyme analysis. The orientation of each insertion was also determined. $\left(^{*}\right) \mathrm{Mu}$ left sequences are nearest attTn7; unmarked insertions are oriented with $\mathrm{Mu}$ right sequences nearest $\operatorname{attTn} 7$. The transposition phenotype of most of the pCW4 :: miniMu $\Omega$ plasmids was determined. Of insertions in pACYC184 sequences, only insertions 38, 16, and 42 were tested. Transposition of miniTn7Cm from the chromosomal att $T n 7$ site to pOX38-Gen and to pOX38-Gen, att $T n 7$ was measured by a mating-out assay. The results were evaluated qualitiatively for miniMu $\Omega$ insertions shown to the left of the vertical box and scores of,-+ , or +++ were assigned. No score is shown for miniMu $\Omega$ insertions not tested. miniMu $\Omega$ insertions shown to the right of the vertical box were also characterized quantitatively. The transposition frequencies shown are the result of one, or are the average of two, independent assays. Both qualitative and quantitative results are shown for some insertions (e.g., all miniMu $\Omega$ insertions in att $T n 7$ ). pCW4 does not promote miniMu $\Omega$ transposition (data not shown). (n.d.) Not determined. 
position levels (average transposition frequency, 2.2 $\mathrm{x} 10^{-4} \mid$, but transposition to pOX was unaffected (average transposition frequency, $1.2 \times 10^{-4}$ ). In vitro transcription and translation of a fragment containing tns $D$ is consistent with this fragment encoding a single polypeptide (C. Waddell and N. Craig, unpubl.) and suggests that the $40-\mathrm{kD}$ protein observed by Brevet et al. (1985) in maxicell experiments was the TnsD protein.

We considered two explanations for transposition to pOX-att $\operatorname{Tn} 7$ observed with $\operatorname{tns} D$ mutations: (1) tnsD mutations eliminate site-specific transposition to att $T n 7$, or (2) tns D mutations affect the frequency, but not the site-specificity, of transposition to att $T n 7$. To distinguish between these two explanations, we determined the position of $\operatorname{Tn} 7$-end derivative insertions within pOX-att $T n 7$ promoted by a tns $D$ mutant. These insertions were not found within the restriction fragment diagnostic of transposition to $\operatorname{att} T n 7$ but rather in several different fragments common to both pOX-att $\operatorname{Tn} 7$ and pOX (Fig. 3, cf. lanes 9-12 to lanes 1-8 and 17). This result provides strong support for the hypothesis that pCW4 derivatives bearing tnsD mutations have lost their capacity to promote transposition to $\operatorname{att} T n 7$ but are unaltered in their ability to promote transposition to other sites.

Thus, we propose that tnsD and tnsE function as target-specific genes; tns $D$ is uniquely required for transposition to $\operatorname{att} T n 7$, whereas $t n s E$ is uniquely required for transposition to sites other than $\operatorname{att} T n 7$.

\section{Identification of tns $\mathrm{A}$, tnsB and tns $\mathrm{C}$}

As noted above, all miniMu $\Omega$ insertions between positions 0.1 and $4.7 \mathrm{~kb}$ (Fig. 2) eliminated the ability of pCW4 to promote transposition to both pOX and pOXatt Tn7. To define the tns genes within this $4.6-\mathrm{kb}$ region, we performed complementation tests between miniMu $\Omega$ insertions in pCW4 and various $\mathrm{Tn} 7$ fragments.

DNA sequencing of the first $540 \mathrm{bp}$ of the right end of $\operatorname{Tn} 7(\mathrm{Tn} 7 \mathrm{R})$ had revealed an ORF beginning approxi- mately at position $0.1 \mathrm{~kb}$, with its promoter $T n 7 \mathrm{R}$ proximal (Gay et al. 1986). Assuming this ORF to encode the amino terminus of $\operatorname{tns} A$, we defined the extent of this gene by determining which $\mathrm{pCW} 4::$ miniMu $\Omega$ plasmids could complement the transposition-defective $\mathrm{Tn} 7 \mathrm{frag}$ ment deleted for this region. As shown in Figure 4A, pCW4 derivatives containing miniMu $\Omega$ insertions to the left of the $0.9-\mathrm{kb}$ BglII site complemented the deletion; i.e., promoted transposition. Thus, the carboxyl terminus of tns $A$ lies between miniMu $\Omega$ insertions 93 (position $0.8 \mathrm{~kb}$ ) and 19 (position $0.95 \mathrm{~kb}$ ). In other complementation tests, we found that the BglII fragment extending from positions 0.04 to $0.9 \mathrm{~kb}$ (see Fig. 4) does not provide functional TnsA (data not shown).

The $\operatorname{tns} A$ analysis above indicates that one end of $\operatorname{tns} B$ must lie between the $0.9-\mathrm{kb} B g I I I$ site and mini$\mathrm{Mu} \Omega$ insertion 19. Complementation tests between various $\mathrm{pCW} 4::$ miniMu $\Omega$ plasmids and a deletion extending into the tns $B$ gene were performed to determine the extent of $\operatorname{tn} s B$. The results indicate that the other end of tns $B$ must lie between miniMu $\Omega$ insertions 89 (position $2.85 \mathrm{~kb}$ ) and 49 (position $3.55 \mathrm{~kb}$ ) (Fig. 4B).

The complementation test in Figure 4B also revealed a third transposition gene in this region, $\operatorname{tns} C$. $\operatorname{tns} C$ is defined by those miniMu $\Omega$ insertions between positions 3.5 and $4.7 \mathrm{~kb}$ that eliminate pCW4-promoted transposition to both pOX and pOX-attTn7 (Fig. 2) and that complement the tnsAB deletion (Fig. 4B). One end of tns C must lie between miniMu $\Omega$ insertions 89 and 49 (Fig. 4B). Smith and Jones (1986) sequenced the BamHI fragment in this region (see Fig. 4) and reported an ORF that starts immediately to the left of the $2.9-\mathrm{kb}$ BamHI site and continues leftward through the fragment. Our results suggest that this ORF encodes the amino terminus of $t n s C$. The capacity of $\mathrm{Tn} 7$ fragments to provide functional tns $A B C$ (see below) is consistent with the carboxyl terminus of tns $C$ lying between miniMu $\Omega 39$ (position $4.65 \mathrm{~kb}$ ) and the $4.7-\mathrm{kb}$ PvuII site.

Both the TnsB and TnsC polypeptides have been identified in maxicells (Brevet et al. 1985; C. Waddell and N. Craig, unpubl.) and have molecular weights in good

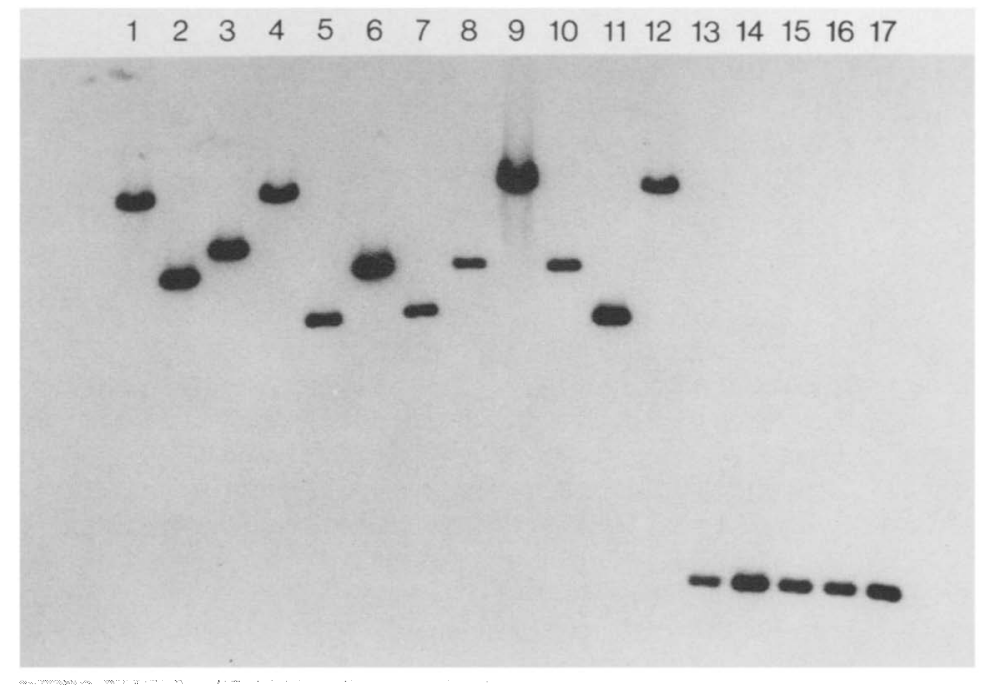

Figure 3. DNA analysis of pCW4:: miniMu $\Omega$-promoted transposition products. Analysis performed as described in the legend to Fig. 1 . The tns and target plasmids are as indicated. (Lanes 1-4) pCW4/pOX as in lanes $5-8$ of Fig. 1 ; (lanes $5-8)$ pCW4 tnsD :: miniMu $\Omega$ 72/pOX; (lanes 9-12) pCW4 tnsD :: miniMu $272 /$ pOXatt Tn7; (lanes 13-16) pCW4 tnsE :: miniMu $\Omega$ 78/pOXattTn7; (lane 17) pCW4/pOX-attTn7 as in lane 1 of Fig. 1. 
agreement with the coding capacity of their respective genes. Truncated polypeptides synthesized from various $\mathrm{pCW} 4 \operatorname{tns} B::$ miniMu $\Omega$ plasmids suggest that the amino

A.

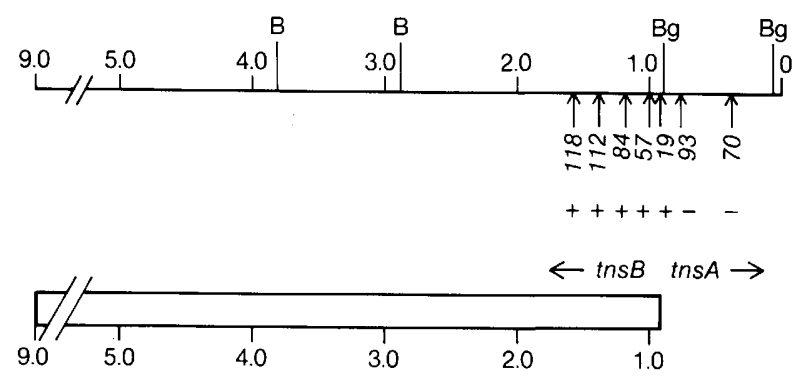

B.

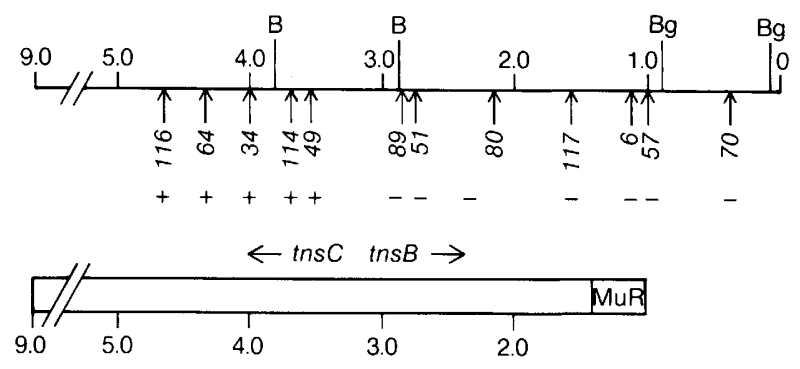

Figure 4. Summary of complementation tests between pCW4 :: miniMu $\Omega$ derivatives (lines) and tns deletion frag. ments (open boxes). The lengths of $\operatorname{Tn} 7$ sequences are shown in $\mathrm{kb}$; vector sequences are not shown. Only $B a m H I$ (B) and $B g l I I$ $(\mathrm{Bg})$ restriction sites are shown. The positions of miniMu $\Omega$ in sertions in pCW4 are indicated by vertical arrows; italicized numbers identify individual insertions. Transposition of miniTn7Cm from the chromosomal att Tn7 site to pOX was measured by a mating-out assay. The ability of each pCW4 :: miniMu $\Omega$ insertion to complement the deletion and promote transposition is indicated by a + or a - . Each insertion was assayed in one to three independent trials. $(A)$ Complementation tests against the tns deletion in pCW12. pCW12 is deleted for all $\mathrm{Tn} 7$ sequences to the right of the $0.9 \mathrm{Bg} / \mathrm{II}$ site. pCW12 does not promote miniTn7Cm transposition laverage transposition frequency $\left.<7.7 \times 10^{-8}\right)$. In these complementation tests, the average - transposition result $=<8.8 \times 10^{-8}$ and the average + transposition result $=9.5 \times 10^{-6}$. This transposition frequency is approximately 16 -fold lower than pCW4-promoted transposition (Table 1) and probably reflects the instability of pCW12. There is measurable loss of pCW12 even under selective growth conditions; only results of matings in which $\geqslant 50 \%$ of the donors retained pCW12 are shown. $(B)$ Complementation tests against the tns deletion in pCW34. pCW34 is deleted for all $\operatorname{Tn} 7$ sequences to the right of mini$\mathrm{Mu} \Omega$ insertion 112 (located at position $1.4 \mathrm{~kb}$ ) and contains the right end of $\mathrm{Mu}$ (MuR). pCW34 does not promote miniTn7Cm transposition (average transposition frequency $=3.5 \times 10^{-8}$ ). In these complementation tests, the average - transposition result $=8.0 \times 10^{-8}$, and the average + transposition result $=7.5 \times 10^{-5}$. terminus of $\operatorname{tns} B$ is near the $\operatorname{tns} A$ gene (C. Waddell and N. Craig, unpubl.).

\section{tns transposition requirements}

What are the minimal tns requirements for transposition? Are tnsD and tnsE essential for transposition, or do they act by stimulating tns $A B C$-dependent transposition? Alternatively, does either tnsD or tnsE have some intrinsic transposition activity in the absence of the other tns genes?

To answer these questions, we examined the ability of fragments containing tns $A B C$, tns $D$, and $t n s E$ to promote transposition individually and in combination. We found that none of the individual tns fragments can promote transposition of miniTn $7 \mathrm{Km}$ (Table 2, sections $1-3)$. The element does transpose, however, when provided with a particular array of tns genes and target sequences. $\operatorname{tn} s A B C+t_{n} D$ promote transposition only if the $\operatorname{att} \operatorname{Tn} 7$ sequence is available (Table 2, section 4); transposition to pOX is not observed. Note that transposition to pOX-attnTn7 promoted by tns $A B C+\operatorname{tns} D$ (pCW23) approaches $100 \%$. Physical analysis of the transposition products confirmed that all miniTn $7 \mathrm{Km}$ insertions occurred into the same fragment of pOXatt $\operatorname{Tn} 7$ (data not shown), consistent with site-specific transposition to att $T n 7$. In contrast, tns $A B C+\operatorname{tns} E$ promote low-frequency transposition to both pOX and

Table 2. tns fragment-promoted transposition

\begin{tabular}{|c|c|c|c|}
\hline \multirow{2}{*}{\multicolumn{2}{|c|}{ tns fragment ${ }^{\mathrm{a}}$}} & \multicolumn{2}{|c|}{ Target plasmid ${ }^{b}$} \\
\hline & & pOX & pOX-att $\operatorname{Tn} 7$ \\
\hline 1. tns $A B C$ & $\begin{array}{l}(\mathrm{pCW} 15) \\
(\mathrm{pCW} 16) \\
(\mathrm{pCW} 21)\end{array}$ & $\begin{array}{r}<2.4 \times 10^{-8} \\
<2.9 \times 10^{-8} \\
4.9 \times 10^{-9}\end{array}$ & $\begin{array}{r}<4.5 \times 10^{-8} \\
<3.6 \times 10^{-8} \\
5.3 \times 10^{-8}\end{array}$ \\
\hline 2. $\operatorname{tns} D$ & $\begin{array}{l}(\mathrm{pCW} 23) \\
(\mathrm{pCW} 25) \\
(\mathrm{pCW} 26)\end{array}$ & $\begin{array}{l}<4.2 \times 10^{-9} \\
<1.9 \times 10^{-8} \\
<4.3 \times 10^{-8}\end{array}$ & $\begin{array}{l}<3.7 \times 10^{-8} \\
<2.5 \times 10^{-8} \\
<6.6 \times 10^{-8}\end{array}$ \\
\hline 3. tnsE & $\begin{array}{l}(\mathrm{pCW} 30) \\
(\mathrm{pCW} 31) \\
(\mathrm{pCW} 32)\end{array}$ & $\begin{array}{l}<4.6 \times 10^{-8} \\
<3.0 \times 10^{-8} \\
<1.2 \times 10^{-8}\end{array}$ & $\begin{array}{l}<9.5 \times 10^{-9} \\
<4.0 \times 10^{-8} \\
<6.8 \times 10^{-8}\end{array}$ \\
\hline 4. $\begin{array}{r}\operatorname{tns} A B C \\
+\operatorname{tns} D\end{array}$ & $\begin{array}{l}\text { (pCW15/pCW23) } \\
\text { (pCW16/pCW23) } \\
\text { (pCW15/pCW25) } \\
\text { (pCW16/pCW25) }\end{array}$ & $\begin{array}{l}<9.9 \times 10^{-9} \\
<7.6 \times 10^{-9} \\
<2.5 \times 10^{-9} \\
<2.8 \times 10^{-9}\end{array}$ & $\begin{array}{l}9.1 \times 10^{-1} \\
1.0 \\
1.5 \times 10^{-1} \\
9.1 \times 10^{-2}\end{array}$ \\
\hline $\begin{aligned} \text { 5. } & \text { tns } A B C \\
+ & \text { tns } E\end{aligned}$ & $\begin{array}{l}\{\mathrm{pCW} 15 / \mathrm{pCW} 30) \\
\text { (pCW16/pCW30) } \\
(\mathrm{pCW} 21 / \mathrm{pCW} 30)\end{array}$ & $\begin{array}{l}4.8 \times 10^{-5} \\
2.0 \times 10^{-4} \\
2.2 \times 10^{-4}\end{array}$ & $\begin{array}{l}2.1 \times 10^{-4} \\
1.2 \times 10^{-4} \\
\quad \text { n.d. }\end{array}$ \\
\hline
\end{tabular}

a ths fragments were tested in different vectors and in different orientations with respect to external vector promoters. pCW23, $\mathrm{pCW} 25$, and $\mathrm{pCW} 30$ are derivatives of $\mathrm{pUC18}$; all other tns plasmids are derivatives of pACYC184.

b Transposition frequencies of miniTn $7 \mathrm{Km}$ from the chromosomal att $T n 7$ site were determined by a mating-out assay. tns and target plasmids are as indicated. Except for tns $A B C$, each number is the average of three to five independent trials. The tns $A B C$ numbers are the result of a single trial. (n.d.) Not determined. 
pOX-attTn7 (Table 2, section 5). These miniTn7Km insertions were found in the fragments common to both target plasmids but never in the fragment unique to pOX-att $T n 7$ (data not shown). We conclude that $\operatorname{Tn} 7$ transposition requires tns $D$ or tnsE in addition to tnsA, tns $B$, and tns $C$ and that tnsD and tnsE specifically promote $\operatorname{Tn} 7$ transposition to different target sequences.

\section{Genetic organization of the tns genes}

Are the tns genes organized in an operon or as separate transcription units? The analysis presented below is consistent with there being four transcription units for the five tns genes: tns $A$ and $t n s B$ comprise an operon, and $t n s C$, tns $D$, and tnsE are transcribed independently. The transcription units were identified based on the ability of miniMu $\Omega$ insertions to exert polar effects on downstream genes in an operon; $\Omega$ is a strongly polar element (Prentki and Krisch 1984; Frey and Frisch 1985).

A fragment containing tns $A$ was unable to complement a tns $A::$ miniMu $\Omega$ mutation in trans (Table 3 , line 3) but did complement a tnsA deletion (line 2). This result suggests that the $\operatorname{tns} A:: \operatorname{miniMu} \Omega$ mutation is polar on $\operatorname{tn} s B$ and, therefore, that $\operatorname{tns} A$ is the first gene in an operon. Presumably, the tns $A$ deletion is not polar on tns $B$ because tns $B$ is transcribed from an external promoter provided by the vector. Sequence analysis of $\operatorname{tn} s A$ (Gay et al. 1986; K. Orle and N. Craig, unpubl.) and part of $\operatorname{tns} B$ (K. Orle and N. Craig, unpubl.) reveals that both genes are transcribed in the same direction, consistent with a tns $A B$ operon. The transcriptional organization of tns $A$ and tns $B$ does not negate our conclusion that tns $A$ is essential for transposition: a wild-type copy of tns $A$ is required in trans to compensate for tns $A$ deletions (Table 3, line 2; Fig. 4A).

Does the tns $A B$ operon include tns $C$ ? The complementation results in Table 3 , column 3 , suggest that it does not. A fragment containing tns $A B$ could comple-

Table 3. Effects of polar insertions in tnsA and tnsB

\begin{tabular}{|c|c|c|c|}
\hline \multirow[b]{2}{*}{ pCW4 derivative } & \multicolumn{3}{|c|}{ Complementing plasmid ${ }^{\mathbf{a}}$} \\
\hline & None & $\begin{array}{l}\operatorname{tns} A \\
\text { (pCW43) }\end{array}$ & $\begin{array}{l}\operatorname{tns} A B \\
\text { (pCW45) }\end{array}$ \\
\hline $\mathrm{pCW}$ & $4.4 \times 10^{-4}$ & $2.5 \times 10^{-5}$ & $2.8 \times 10^{-5}$ \\
\hline$\Delta \operatorname{tns} A(\mathrm{pCW} 51)$ & $<1.3 \times 10^{-8}$ & $2.4 \times 10^{-6}$ & $5.7 \times 10^{-6}$ \\
\hline $\operatorname{tns} A:: \operatorname{miniMu} \Omega 81$ & $<7.7 \times 10^{-8}$ & $2.4 \times 10^{-8}$ & $1.6 \times 10^{-5}$ \\
\hline $\operatorname{tns} B:: \operatorname{miniMu} \Omega 57$ & $<6.9 \times 10^{-8}$ & n.d. & $2.9 \times 10^{-5}$ \\
\hline $\operatorname{tns} B:: \operatorname{miniMu} \Omega 11$ & $<3.3 \times 10^{-8}$ & n.d. & $7.1 \times 10^{-6}$ \\
\hline $\mathrm{iMu} \Omega 89$ & n.d. & n.d. & $6.0 \times 10^{-6}$ \\
\hline $\operatorname{tns} C:: \operatorname{mini} M u \Omega 34$ & $<1.4 \times 10^{-7}$ & n.d. & $<7.4 \times 10^{-9}$ \\
\hline
\end{tabular}

a Transposition frequencies of miniTn $7 \mathrm{Km}$ from the chromosomal $\operatorname{att} \operatorname{Tn} 7$ site to pOX were determined by a mating-out assay. tns plasmids are as indicated. $\mathrm{pCW} 4:$ :miniMu $\Omega$ numbers from Fig. 2. All other numbers are the average of three to five independent trials. n.d. $=$ not determined. We note that $t$ ns $A$ and tns $A B$-complemented transposition frequencies are $\geqslant 15$ fold lower than pCW4-promoted transposition. This may be an effect of multicopy Tn7 right end sequences (L. Arciszewska and N. Craig, in prep.) or multicopy TnsA.
Table 4. Effects of polar insertions in tnsC

\begin{tabular}{lc}
\hline tns $C D$ plasmida & $\begin{array}{l}\text { tns } A B C^{\mathrm{b}} \\
\text { (pCW15) }\end{array}$ \\
\hline tns CD (pCW52) & $1.5 \times 10^{-2}$ \\
tns $C:$ :miniMu 34 tnsD (pCW54) & $2.4 \times 10^{-3}$ \\
tns $C:$ :miniMu 39 tnsD (pCW55) & $1.5 \times 10^{-4}$ \\
tns CD (pCW53) & $3.9 \times 10^{-1}$ \\
tns $C:$ :miniMu 39 tnsD (pCW56) & $1.1 \times 10^{-2}$ \\
- & $<4.5 \times 10^{-8}$
\end{tabular}

a In pCW52, pCW54, and pCW55, the tns fragment is oriented so that tnsC is adjacent to vector Plac; in pCW53 and pCW56, tns $D$ is adjacent to vector Plac.

b Transposition frequencies of miniTn $7 \mathrm{Km}$ from the chromosomal $a t t T n 7$ site to pOX-att $\operatorname{Tn} 7$ were determined by a matingout assay. tns plasmids are as indicated. To ensure that the transposition frequencies reflected only tnsD-promoted events to $\operatorname{att} \operatorname{Tn} 7, \operatorname{tns} E$ was not present in these experiments. $\operatorname{tns} A B C$ number is from Table 2 . All other numbers are the average of three to five independent trials.

ment both a tnsA deletion (line 2) and a $\operatorname{tns} A::$ mini$\mathrm{Mu} \Omega$ mutation (line 3 ), as well as three different tns $B::$ miniMu $\Omega$ mutations (lines 4-6) and was unable to complement a tns $C:: \operatorname{miniMu} \Omega$ mutation (line 7$)$. These results suggest that the operon is limited to the tns $A$ and $\operatorname{tns} B$ genes.

What is the relationship of the tns $C$ and tnsD genes? An operon with tnsD promoter proximal to tns $C$ is unlikely. $t n s D::$ miniMu $\Omega$ mutants are unaltered in tnsEdependent transposition (Fig. 2), an event that requires tns C. Moreover, limited sequence analysis of tnsC (Smith and Jones 1986) and tnsD (K. Orle and N. Craig, unpubl.) suggests that these two genes are transcribed in the same direction but in the opposite orientation predicted for a $\operatorname{tns} D C$ operon.

Do the tnsC and tnsD genes comprise an operon with tns $C$ promoter proximal? We interpret the results in Table 4 to indicate that $\operatorname{tns} C:: \operatorname{miniMu} \Omega$ mutants are not polar on tns $D$ and, therefore, that tns $C$ and $\operatorname{tns} D$ are separate transcription units. Each of the tns $C::$ mini$\mathrm{Mu} \Omega$ tns $D$ plasmids tested could complement the tns $A B C$ plasmid and promote transposition to pOXatt $\operatorname{Tn} 7$ (cf. lines, 2, 3, and 5 to line 6). However, mini$\mathrm{Mu} \Omega$ insertions in $\operatorname{tns} C$ decrease the frequency of transposition (cf. lines 2 and 3 to line 1 , and line 5 to line 4 ). This inhibitory effect was most pronounced for plasmids in which the amino terminus of $t n s C$ was proximal to an external vector promoter (lines $1-3$ ) and was markedly less severe for plasmids in which the carboxyl terminus of tns $D$ was promoter proximal (lines 4 and 5). Because the observed orientation effect is inconsistent with a tns $C D$ operon, we suggest that the decreased transposition frequencies reflect properties of the plasmid constructions. Perhaps an in-frame $\mathrm{TnsC}$ fusion protein or an abundance of a truncated $\mathrm{TnsC}$ polypeptide that has an inhibitory effect in trans was created in these plasmids.

Direct examination of TnsD and TnsE mutant phenotypes indicate that these two genes are transcribed independently of one another. miniMu $\Omega$ insertions in either 
gene have no effect on the transposition pathway promoted by the other (see Fig. 2).

\section{Effect of increased copy number of ths genes on Tn7 transposition}

Transposition of intact $\mathrm{Tn} 7$ was measured in the presence of plasmids containing a tnsD or a tnsE fragment. $\operatorname{Tn} 7$ transposition to pOX decreased approximately fivefold in the presence of tnsD plasmids (Table 5), whereas transposition to pOX-att $T n 7$ decreased approximately five-fold in the presence of two tnsE plasmids (Table 5, pCW31 and pCW32). It is tempting to speculate that we have created cellular conditions in which TnsD and TnsE are competing for some limiting component of the transposition machinery. pCW4 had no significant effect on $\operatorname{Tn} 7$ transposition (data not shown).

The results in Table 5 also show that none of the tns $D$ or tnsE plasmids significantly increased $\operatorname{Tn} 7$ transposition to either target plasmid. Smith and Jones (1984) found that the tnsE gene in multicopy stimulated $\operatorname{Tn} 7$ transposition approximately 30 -fold. We note that several features of the two studies differ; perhaps different rate-limiting determinants were measured. Although our assays measured transposition of $\mathrm{Tn} 7$ from chromosomal att $T n 7$ to an IncFI conjugable plasmid (pOX), whereas Smith and Jones measured transposition of $\operatorname{Tn} 7$ from a site in the multicopy plasmid ColE1 to an IncP conjugable plasmid. The ColE1 insertion site shows no sequence homology to attTn7 (Lichtenstein and Brenner 1982), suggesting that the original transposition event was promoted by tnsE (K. Kubo and N. Craig, in prep.). Experiments measuring transposition from a tnsE site in an $\mathrm{F}^{\prime}$ episome demonstrated that transposition from a tnsE site requires the same set of tns genes as does transposition from $\operatorname{att} \operatorname{Tn} 7$ (N. Craig and C. Waddell, unpubl.). However, these experiments do not address the level of Tns proteins required in the two different reactions.

\section{Discussion}

Our analysis of the transposition genes of $\operatorname{Tn} 7$ has added to this transposon's list of distinguishing characteristics. We have identified a surprisingly complex array of five
Table 5. Tn7 transposition in the presence of multicopy $\mathrm{tnsD}$ and tnsE

\begin{tabular}{llcc}
\hline & & \multicolumn{2}{c}{ Target plasmida } \\
\cline { 3 - 4 } tns plasmid & pOX & pOX-attTn7 \\
\hline b $^{\mathrm{b}}$ & & $1.7 \times 10^{-4}$ & $9.4 \times 10^{-3}$ \\
tnsD & (pCW23) & $2.6 \times 10^{-5}$ & $2.2 \times 10^{-2}$ \\
& (pCW25) & $4.2 \times 10^{-5}$ & $1.2 \times 10^{-2}$ \\
& (pCW26) & $2.5 \times 10^{-5}$ & $1.6 \times 10^{-2}$ \\
tnsE & (pCW30) & $5.5 \times 10^{-5}$ & $5.3 \times 10^{-3}$ \\
& (pCW31) & $5.3 \times 10^{-5}$ & $1.6 \times 10^{-3}$ \\
& (pCW32) & $4.7 \times 10^{-5}$ & $1.8 \times 10^{-3}$ \\
\hline
\end{tabular}

a Transposition frequencies of Tn7 from the chromosomal att $T n 7$ site were determined by a mating-out assay. tns and target plasmids are as indicated. Each number is the average of three to nine independent trials.

b Numbers from L. Arciszewska and N. Craig (in prep.)

tns genes, tns $A$, tns $B$, tns $C$, tns $D$, and tns $E$, that have essential roles in transposition. No other characterized transposon has such an elaborate array of transposition genes; most other transposons encode one or two proteins with essential transposition functions (reviewed in Kleckner 1981; Shapiro 1983; Grindley and Reed 1985). Our study of the tns genes employed a novel insertional mutagenesis procedure. In an in vitro $\mathrm{Mu}$ transposition reaction, a polar miniMu $\Omega$ element was transposed to sequences within the tns plasmid pCW4. Analysis of the disrupted pCW4 derivatives led to the identification and characterization of the tns genes. Among the many useful features of this mutagenesis procedure are the large number of independent insertions produced in a single in vitro reaction, the creation of many different antibiotic-resistant insertions throughout the target DNA sequences, and the potential use of these insertions as convenient priming sites for DNA sequence analysis (Adachi et al. 1987). The position and orientation of the five tns genes within Tn7 are diagramed in Figure 5. All five tns genes are transcribed in the same direction. Our analysis of polar effects of the tns :: mini$\mathrm{Mu} \Omega$ insertions is consistent with the hypothesis that

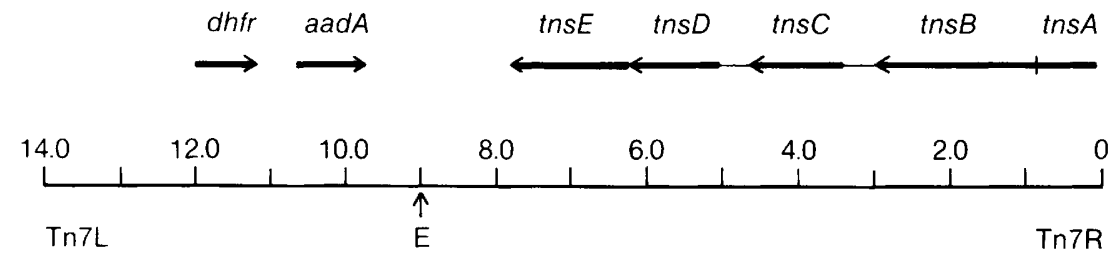

Figure 5. Diagram of $\operatorname{Tn} 7$. $\operatorname{Tn} 7 \mathrm{~L}$ and $\operatorname{Tn} 7 \mathrm{R}$ designate the left and right ends of $\operatorname{Tn} 7$, respectively. Numbers indicate the length of $\operatorname{Tn} 7$ in $\mathrm{kb}$. The position of the unique EcoRI site $(\mathrm{E})$ in $\mathrm{Tn} 7$ is indicated by the vertical arrow. Horizontal arrows indicate the position and direction of transcription of the Tn7-encoded genes. dhfr encodes a dihydrofolate reductase (Fling and Richards 1983) that confers resistance to trimethoprim, and aadA encodes a $3^{\prime \prime}(9)-O$-nucleotidyltransferase (Fling et al. 1985) that provides resistance to streptomycin/spectinomycin. tnsA-tnsE are transposition genes of $\operatorname{Tn} 7$. The boundaries and directions of these genes were determined by the the analysis of miniMu $\Omega$ insertions in pCW4 and of fragments containing tns genes (thick lines) and limited sequence analysis (thin lines) (Smith and Jones 1986; K. Orle and N. Craig, unpubl.). 
tns $A$ and tns $B$ comprise an operon, whereas tns $C$, tns $D$, and tnsE are separate transcription units. We note, however, that substantial polar effects on tns gene expression may not have been detected in our transposition assays. A definitive view of the transcriptional organization of the tns genes must await direct analysis of the tns transcripts.

\section{The role of tnsD and tnsE in transposition}

The large number of tns genes is explained in part by the finding that $\mathrm{Tn} 7 \mathrm{can}$ participate in either of two transposition pathways in which transposition is directed by one of two target-specific genes, tnsD or tnsE. Tn7-end derivatives transpose efficiently and exclusively to $\operatorname{att} T n 7$ when provided $\operatorname{tns} A, \operatorname{tns} B, \operatorname{tns} C$, and $\operatorname{tn} s D$. If tnsE is substituted for $t n s D$, other target sites are used at a low frequency and $\operatorname{att} \operatorname{Tn} 7$ is ignored. $\operatorname{tn} s A, \operatorname{tns} B$, and tns $C$ are absolutely required in both transposition pathways. A similar view of the roles of tnsD and tnsE in target selection has emerged in studies in which the E. coli chromosome serves as the transposition target (K. Kubo and N. Craig, unpubl.). Rogers et al. (1986) also showed that $t n s D$ and tnsE promote transposition to different target sites; however, they did not demonstrate a requirement for $\operatorname{tns} A$, tns $B$, and $\operatorname{tns} C$ in tnsE-promoted transposition. It will be interesting to determine how the TnsD and TnsE proteins select Tn 7 target sites and what role these proteins have in establishing the frequency of transposition in the two transposition pathways.

The existence of target-specific proteins is another novel feature of $\operatorname{Tn} 7$ transposition. In the transposition of phage $\mathrm{Mu}$, one of two element-encoded transposition proteins, $\mathrm{Mu} \mathrm{B}$, binds nonspecifically to DNA /Chaconas et al. 1985) and presumably interacts with target DNA. Although the Mu B protein may facilitate $\mathrm{Mu}$ end capture by target DNA molecules, its participation in the transposition reaction differs from that of TnsD and TnsE in two important respects: $\mathrm{Mu} \mathrm{B}$ does not direct selection of a specific target sequence and some $\mathrm{Mu}$ transposition can occur in the absence of $\mathrm{Mu} B(R$. Craigie, M. Mizuuchi, and K. Mizuuchi, pers. comm.).

\section{The role of tnsB in transposition}

tns $B$ mutants are completely defective in both $\operatorname{Tn} 7$ transposition pathways and, therefore, must lack a function common to all transposition events. We believe this function is utilization of cis-acting sequences at the ends of Tn7. An integral step in all transposition models is the identification and cleavage of sequences at the termini of the transposon (Berg 1977; Grindley and Sherratt 1978; Shapiro 1979). Biochemical studies in our laboratory have identified a tns $B$-dependent DNA-binding activity that specifically recognizes sequences present in both ends of $\operatorname{Tn} 7$ (McKown et al. 1987). This activity does not require the gene products of tns $A, \operatorname{tns} C$, tnsD, or tnsE (McKown et al. 1987). It is not yet known whether TnsB has any other enzymatic activity in addi- tion to its proposed DNA-binding activity. Binding to specific end sequences has also been observed with $\mathrm{MuA}$ of $\mathrm{Mu}$, InsA of IS1, and with transposases of the Tn3 family (Craigie et al. 1984; Wishart et al. 1985; Zerbib et al. 1987; L. Wiater and N. Grindley, pers. comm.). Several lines of evidence suggest that TnsB also has a regulatory role in tns gene expression (Rogers et al. 1986; McKown et al. 1987).

\section{The role of tnsA and tns $\mathrm{C}$ in transposition}

Our studies have demonstrated that both $\operatorname{tns} A$ and $\operatorname{tns} C$ are essential for all $\mathrm{Tn} 7$ transposition events but have not defined specific functions for the $\operatorname{tns} A$ and $t n s C$ gene products. We can exclude the possibility that one of these gene products acts only as a site-specific recombinase to resolve cointegrate transposition products. Neither a tnsA deletion nor disruptions in any of the tns genes resulted in cointegrate transposition products when we assayed miniTn $7 \mathrm{Cm}$ transposition from a plasmid (C. Waddell and N. Craig, unpubl.).

How might the tns $A$ and tns $C$ gene products participate in transposition? Although many models can be evoked, three particularly intriguing possibilities are worthy of mention. Perhaps one of these proteins functions in synapsis of donor and target sequences by serving as a 'linker protein' that recognizes both TnsB and the target proteins TnsD and TnsE. This model is analogous to the role of $P$ protein in $\lambda$ replication (reviewed in Furth and Wickner 1983). Perhaps, the transposase enzymatic activity of $\operatorname{Tn} 7$ is not encoded in a single gene but is produced upon the formation of a multicomponent Tns protein complex. Several transposition reactions require host proteins such as IHF or HU, in addition to element-encoded proteins (Craigie et al. 1985; Morisato and Kleckner 1987). IHF has no detectable role in $\mathrm{Tn} 7$ transposition (K. Kubo and N. Craig, unpubl.); perhaps tns $A$ or tns $C$ encodes a functional analog of IHF or of another host protein. These last two scenarios would help account for the surprisingly large number of $\operatorname{Tn} 7$ transposition genes.

\section{Concluding remarks}

Our identification and characterization of the tns genes of $\operatorname{Tn} 7$ has led to the following model of $\operatorname{Tn} 7$ transposition:

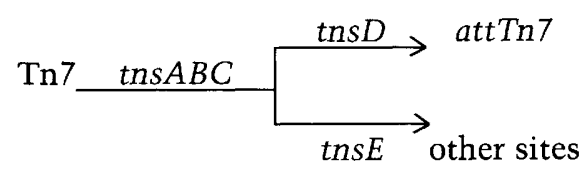

It will be interesting to elucidate the mechanism(s) by which the $t n s$ gene products mediate Tn7 transposition.

\section{Materials and methods}

Media, chemicals, and enzymes

LB broth and agar were used, as described by Miller (1972), except that $1 \mathrm{mg} / \mathrm{ml}$ glucosamine was added to agar. Trimetho- 
prim selection was on Isosensitest agar (Oxoid). Antibiotic concentrations used were $100 \mu \mathrm{g} / \mathrm{ml}$ carbenicillin $(\mathrm{Cb}), 30 \mu \mathrm{g} / \mathrm{ml}$ chloramphenicol $(\mathrm{Cm}), 10 \mu \mathrm{g} / \mathrm{ml}$ gentamycin (Gen), $50 \mu \mathrm{g} / \mathrm{ml}$ kanamycin $(\mathrm{Km}), 20 \mu \mathrm{g} / \mathrm{ml}$ nalidixic acid $(\mathrm{Nal}), 50$ or $500 \mu \mathrm{g} / \mathrm{ml}$ spectinomycin (Sp), $50 \mu \mathrm{g} / \mathrm{ml}$ streptomycin $(\mathrm{St}), 5$ or $20 \mu \mathrm{g} / \mathrm{ml}$ tetracycline (Tc), and $100 \mu \mathrm{g} / \mathrm{ml}$ trimethoprim (Tp). DNA-modifying enzymes were obtained from commercial sources and used as recommended by the manufacturer.

\section{Strains}

NLC51 is $\mathrm{F}^{-}$araD1394(argF-lac)U169 rpsL150 relA1 flbB5301 deoC1 ptsF25 rbsR val ${ }^{R}$ recA56 (McKown et al. 1987). CW51 is $\mathrm{F}^{-}$ara $^{-}$arg- $^{-}$lac proXIII nal ${ }^{R}$ rif $^{R}$ recA56 and was obtained by replacing $\mathrm{F}^{\prime} l a c I^{\mathrm{Q}} \mathrm{L8}$ pro $^{+}$in NK5830 (N. Kleckner, Harvard University) with $\mathrm{F}^{\prime}$ ts $\mathrm{lac}^{+}:: \mathrm{Tn} 7$ by plasmid exclusion and isolating a $\mathrm{Tp}^{S} \mathrm{lac}^{-}$derivative after growth at $42^{\circ} \mathrm{C}$. All other strains in this work are derivatives of NLC51, in which (1) Tn7, or a Tn7-end element, occupies the chromosomal attTn7 site, (2) a conjugable plasmid, pOX38-Gen or pOX38-Gen, att $\operatorname{Tn} 7$, is present, and (3) one or two ths plasmids is present. Chromosomal att $\operatorname{Tn} 7$ insertions were obtained as follows. Tn7, or a Tn7-end element, was introduced on a conjugable plasmid into NLC51 or NLC51 pCW4, respectively. The element-bearing plasmid was lost either by plasmid exclusion or by growth under nonpermissive conditions, and isolates that retained the Tn7-end element-encoded drug resistance were recovered. Insertions into the chromosomal att Tn 7 site were verified by P1 transduction or by physical analysis using Southern blots (data not shown). Plasmids were introduced into strains following standard conjugation (Miller 1972) or transformation (Maniatis et al. 1982) techniques.

\section{Tn7 derivatives}

The derivative of $\operatorname{Tn} 7$ used in this laboratory, $\mathrm{Tn} 7 \mathrm{~S}$, contains an IS1 element near the drug-resistance determinants of $\operatorname{Tn} 7$; however, the transposition properties of $\mathrm{Tn} 7 \mathrm{~S}$ are indistinguishable from those of canonical $\operatorname{Tn} 7$ (Hauer and Shapiro 1984). miniTn $7 \mathrm{Cm}$ is $\operatorname{Tn} 7 \mathrm{~S}::$ Tn9 9 PstI (Hauer and Shapiro 1984) and contains approximately $1.9 \mathrm{~kb}$ of the left end of $\operatorname{Tn} 7$ and $537 \mathrm{bp}$ of the right end of Tn7, flanking the chloramphenicol-resistance determinant of $\mathrm{Tn} 9$. miniTn $7 \mathrm{Km}$ (McKown et al. 1988) contains $166 \mathrm{bp}$ of the left end of Tn7 and $199 \mathrm{bp}$ of the right end of $\operatorname{Tn} 7$, flanking a segment encoding kanamycin resistance. mini $T n 7 \mathrm{Km}$ contains all the essential sequences at the termini of $\operatorname{Tn} 7$ required for transposition (L. Arciszewska and N. Craig, in prep.).

\section{Manipulation and characterization of DNA}

Plasmid growth, isolation, restriction enzyme analysis, and transformation were performed as described by Maniatis et al. (1982). Recombinant molecules were made using standard cloning techniques, described by Maniatis et al. (1982), except that usually DNA fragments were contained in slices from low-melting-temperature agarose gels (Sea Plaque), as described by Struhl (1983).

\section{Plasmids}

pOX38-Gen (Johnson and Reznikoff 1984) is a transfer proficient derivative of the conjugable plasmid $\mathrm{F}$ and lacks $\gamma \delta$ or IS elements. pOX38-Gen, attTn7 (L. Arciszewska and N. Craig, in prep.) is the same as pOX38-Gen, except that it carries a transposition-defective, tetracycline-resistant derivative of Tn10 that contains attTn7.

See Figures 2 and 6 for the location of restriction sites and miniMu $\Omega$ insertions utilized in formation of the following plasmids.

pCW4 was described previously (McKown et al. 1987) and contains approximately $9 \mathrm{~kb}$ of $\mathrm{Tn} 7$, extending from the unique EcoRI site at position 9.0 through the right end of $\operatorname{Tn} 7$ and 165 bp of flanking attTn 7 sequence inserted into the EcoRI site of pACYCl84, with att $T n 7$ near vector Pcat.

pCW10. The EcoRI-BglII fragment containing tnsA-tnsE was inserted into EcoRI-BamHI-digested pUC19.

pCW12. The EcoRI-BglII fragment containing tns B-tnsE was inserted into EcoRI-BamHI-digested pUC19.

pCW15 and pCW16. The PvuII-PvuII fragment from pCW4 containing $\operatorname{tns} A$, tns $B$, and tns $C$ was inserted into the Klenowtreated SalI site of pACYC184, with tnsC near vector Ptc (pCW15) or with tnsA near vector Ptc (pCW16).

pCW21. The EcoRI-EcoRI fragment from pCW4 :: miniMu $\Omega$ 47 containing $\operatorname{tns} A, \operatorname{tns} B$, and $\operatorname{tns} C$ was inserted into the EcoRI site of pACYC184, with tnsA near vector Pcat.

pCW23, pCW25, and pCW26. The HpaI-EcoRI fragment from pCW4 :: miniMu $\Omega 39$ containing tnsD was treated with Klenow fragment to repair the EcoRI end and was inserted into the HincII site of pUC18 with the Mu sequences adjacent to vector Plac (pCW23) or with the HindIII site near vector Plac (pCW25), or into the Klenow-treated SalI site of pACYC184, with the HindIII site near vector Ptc (pCW26).

pCW30, pCW31, and pCW32. The HindIII-HindIII fragment from pCW4 containing tnsE was inserted into the HindIII site of pUC18, with the BstEII site near vector Plac, (pCW30) or into

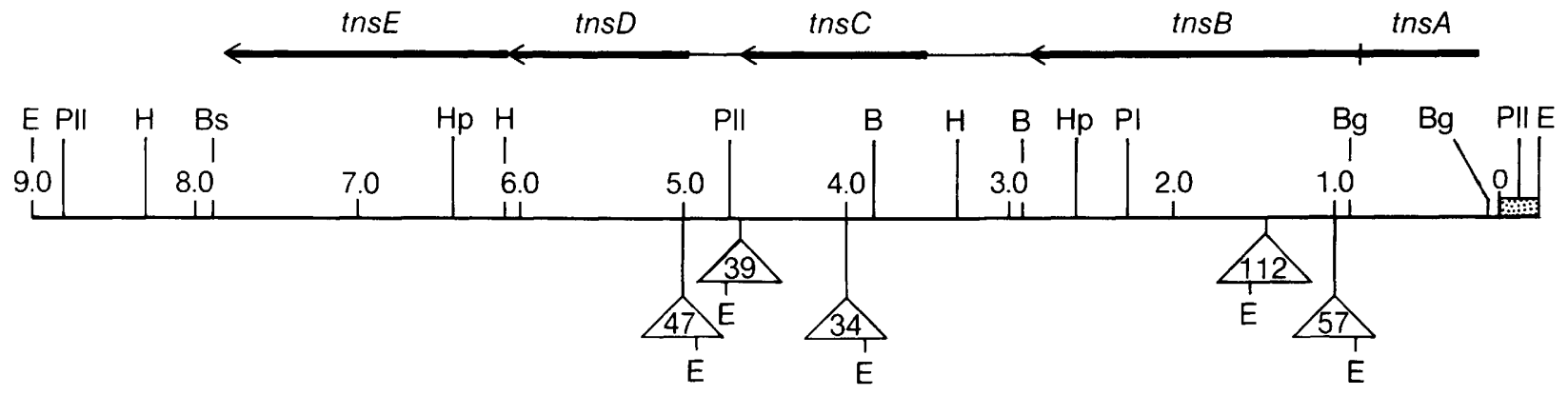

Figure 6. Diagram of $\operatorname{Tn} 7$ fragment in pCW4. The line represents $\operatorname{Tn} 7$ sequences, and the speckled box designates flanking attTn7 DNA. The tns genes are shown as in Fig. 5. The positions of miniMu $\Omega$ insertions in pCW4 derivatives used in the formation of recombinant plasmids are indicated. The miniMu $\Omega$ are not drawn to scale, and only the EcoRI site is shown. A partial restriction map of the Tn7 fragment is also shown. (B) BamHI; (Bg) BgIII; (Bs) BstEII; (E) EcoRI; (H) HindIII; (Hp) HpaI; (PI) PvuI; (PII) PvuII. 
the HindIII site of pACYC184, with the BstEIII site near vector Ptc (pCW31) or with the HpaI site near vector Ptc (pCW32).

pCW34. The EcoRI-EcoRI fragment from pCW4 :: miniMu $\Omega$ 112 containing $\operatorname{tns} E$, $\operatorname{tn} s D$, tns $C$, and part of $\operatorname{tn} s B$ was inserted into the EcoRI site of $\mathrm{pUCl}$, with the $\mathrm{Mu}$ sequences adjacent to vector Plac.

pCW43. The EcoRI-BglII fragment from pCW4 :: miniMu $\Omega$ 57 containing the tns $A$, tns $B$ junction and the BglII-HindIII fragment from pCW10 contaning most of $t n s A$ were inserted into EcoRI-HindIII-digested pUC19.

pCW45. The HindIII-HindIII fragment from pCW10 containing tns $A$ and $\operatorname{tns} B$ was inserted into the HindIII site of pUC18, with tnsA near vector Plac.

pCW51. The BglII-BglII fragment of pCW4 containing most of tns $A$ was deleted.

pCW52 and pCW53. The HpaI-HpaI fragment from pCW4 containing $\operatorname{tns} C$ and tns $D$ was inserted into the HincII site of pUC18, with tnsC near vector Plac (pCW52) or with tnsD near vector Plac (pCW53).

pCW54. The HpaI-HpaI fragment from pCW4 :: miniMu $\Omega$ 34 containing tns $C::$ miniMu $\Omega 34$ and $\operatorname{tns} D$ was inserted into the HincII site of pUC18, with tnsC :: miniMu $\Omega 34$ near vector Plac.

pCW55 and pCW56. The HpaI-HpaI fragment from pCW4 :: miniMu 39 containing tns $C:: \operatorname{miniMu} \Omega 39$ and tnsD was inserted into the HincII site of pUC18, with tnsC :: miniMu 39 near vector Plac (pCW55) or with tnsD near vector Plac (pCW56).

\section{miniMu $\Omega$ transposition reaction}

The miniMu $\Omega$ plasmid pMK386 was made by Dr. Robert Craigie (NIH). pMK386 is the same as pMK26 (a derivative of pMK108) (Mizuuchi 1983; Craigie and Mizuuchi 1986), except that the BamHI $\Omega$ fragment from pHP45 $\Omega$ (Prentki and Krisch 1984) is inserted at the BamHI site in the Mu part of pMK26.

The miniMu $\Omega$ transposition reaction was carried out by $R$. Craigie. pMK386 and pCW4 were the DNA substrates for the in vitro Mu DNA strand-transfer reaction, as described in Craigie et al. (1985). The resulting transposition intermediates were resolved, as described in Craigie and Mizuuchi (1985). The resolved transposition products were digested with AatII, a restriction enzyme that cleaves pMK386 outside of the miniMu $\Omega$ sequences, to linearize cointegrate products, intramolecular rearrangements of pMK386, and unreacted pMK386. There is no AatII site in pCW4. The DNA was then treated with pronase, phenol extracted, ethanol precipitated, and suspended in $30 \mu \mathrm{l}$ of $10 \mathrm{~mm}$ Tris ( $\mathrm{pH} 8.0$ ), $0.5 \mathrm{~mm}$ EDTA.

One microliter of a 1:10 dilution was used to transform competent HB101 cells (Boyer and Roulland-Dussoix 1969). Of the $127 \mathrm{Tc}^{\mathrm{R}} \mathrm{Sp}^{\mathrm{R}}$ transformants tested, 9 were also $\mathrm{Cb}^{\mathrm{R}}$, indicating that pMK386 was present in addition to pCW4. Restriction analysis of plasmid DNA from the $118 \mathrm{Cb}^{\mathrm{s}}$ transformants revealed that 96 of the plasmids contained a single simple insertion of miniMu $\Omega$ into pCW4, whereas 22 were the result of multiple miniMu $\Omega$ transposition events and were not characterized further. The positions of miniMu $\Omega$ insertions were determined by PvuII and PvuI restriction analysis of plasmid DNA; orientation was determined by EcoRI or SphI restriction analysis. The map position of each insertion was determined to an accuracy of at least $\pm 200 \mathrm{bp}$. The positions of various mini$\mathrm{Mu} \Omega$ insertions with respect to $\mathrm{Tn} 7$ restriction sites were also determined. Among the sites analyzed were BamHI, BglII, BstEII, HindII, and HpaI. The positions of these sites within the Tn7 fragment in pCW4 are diagramed in Figures 2 and 6 . There is no SphI site in the Tn7 fragment, and there are no BglII, $\mathrm{HpaI}$, or PvuII sites in miniMu $\Omega$.

\section{Transposition assay}

Transposition frequencies were determined by a mating-out assay. For each strain tested, individual single colonies were inoculated into LB broth with the appropriate selective antibiotic. Cultures were grown at $37^{\circ} \mathrm{C}$ to an $\mathrm{OD}^{600}$ of approximately 0.4 and used directly or were grown overnight to saturation, subcultured, and grown to the appropriate density. Each culture was mixed with the recipient strain, also grown to an $\mathrm{OD}^{600}$ of 0.4 , at a ratio of $1: 10$, donor : recipient. The recipient strain was always CW51, and donor strains were derivatives of NLC51 pOX38-Gen or NLC51 pOX38-Gen, attTn7. The mating mixture was incubated at $37^{\circ} \mathrm{C}$ with gentle aeration. After 60 $\mathrm{min}$, the mixture was vortexed vigorously, placed on ice, and aliquots plated. The total number of exconjugants was determined by selection of Gen ${ }^{R}$ iff $^{R}$ colonies. The number of exconjugants that had acquired a $\operatorname{Tn} 7$ derivative was determined by selection of $\mathrm{Tp}^{\mathrm{R}} \mathrm{Rif}^{\mathrm{R}}, \mathrm{Cm}^{\mathrm{R}} \mathrm{Rif} \mathrm{R}^{\mathrm{R}}$, or $\mathrm{Km}^{\mathrm{R}} \mathrm{Rif}^{\mathrm{R}}$ colonies for $\mathrm{Tn} 7$, mini $T n 7 \mathrm{Cm}$, or miniTn $7 \mathrm{Km}$ transposition, respectively. The transposition frequency is expressed as the total number of $\operatorname{Tn} 7$ derivative-containing exconjugants divided by the total number of exconjugants. In qualitative mating-out assays, the total number of exconjugants was not determined.

\section{Southern blot hybridization analysis}

Total DNA was digested with EcoRI, electrophoresed in $0.6 \%$ agarose, and transferred to Nytran (Schleicher and Schuell) in $10 \times$ SSC. Filters were hybridized at $42^{\circ} \mathrm{C}$ in $50 \%$ formamide, $10 \times$ Denhart's solution, $0.1 \%$ SDS, $0.01 \%$ salmon sperm DNA, $0.05 \%$ sodium pyrophosphate, $1 \mathrm{~mm}$ EDTA, $10 \mathrm{~mm}$ HEPES (pH 7.5), and $3 \times$ SSC. Filters were washed at $42^{\circ} \mathrm{C}$ in $1 \times$ SSC, $0.1 \%$ SDS twice for $30 \mathrm{~min}$. The hybridization probe was the nick-translated kanamycin fragment of miniTn $7 \mathrm{Km}$. Nick-translation was performed according to standard procedures (Maniatis et al. 1982).

\section{Acknowledgments}

We are deeply grateful to Bob Craigie and Kiyoshi Mizuuchi for construction of miniMu $\Omega$, in vitro mutagenesis of $\mathrm{pCW} 4$, and helpful discussions. We thank Pierre Prentki for pHP45 $\Omega$, Nancy Kleckner for NK5830, Ken Kubo for help with the Southern analysis, other members of the Craig laboratory for useful discussions throughout this work, and Karyl Nakamura for excellent preparation of the manuscript. We also thank Mark Rogers and Dave Sherratt for useful discussions in naming the tns genes. Ira Herskowitz, Lorraine Marsh, and Susan Michaelis provided valuable discussions and comments on the manuscript. C.S.W. was supported by a National Science Foundation Fellowship. The work was supported by a grant from the National Institutes of Allergies and Infectious Diseases to N.L.C.

\section{References}

Adachi, T., M. Mizuuchi, E.A. Robinson, E. Appella, M.H. O'Dea, M. Gellert, and K. Mizuuchi. 1987. DNA sequence of the $E$. coli gyrB gene: Application of a new sequencing strategy. Nucleic Acids Res. 15: 771-784.

Barth, P.T. and N.J. Grinter. 1977. Map of plasmid RP4 derived by insertion of transposon C. J. Mol. Biol. 113: 455-474.

Barth, P.T., N.J. Grinter, and D.E. Bradley. 1978. Conjugal transfer system of plasmid RP4: Analysis by transposon 7 insertion. J. Bacteriol. 133: 43-52.

Barth, P.T., N. Datta, R.W. Hedges, and N.J. Grinter. 1976. Transposition of a deoxyribonucleic acid sequence encoding 
trimethoprim and streptomycin resistances from R483 to other replicons. J. Bacteriol. 125: 800-810.

Berg, D.E. 1977. Insertion and excision of the transposable kanamycin resistance determinant Tn5. In DNA insertion elements, plasmids, and episomes (ed. A.I. Bukhari, J.A. Shapiro, and S.L. Adhya), pp. 205-212. Cold Spring Harbor Laboratory, Cold Spring Harbor, New York.

Boyer, H.W. and D. Roulland-Dussoix. 1969. A complementation analysis of the restriction and modification of DNA in Escherichia coli. J. Mol. Biol. 41: 459-472.

Brevet, J., F. Faure, and D. Borowski. 1985. Tn7-encoded proteins. Mol. Gen. Genet. 201: 258-264.

Chaconas, G., G. Gloor, and J.L. Miller. 1985. Amplification and purification of the bacteriophage $\mathrm{Mu}$ encoded $B$ transposition protein. J. Biol. Chem. 260: 2662-2669.

Chang, A.C.Y. and S.N. Cohen. 1978. Construction and characterization of amplifiable multicopy DNA cloning vehicles derived from the P15A cryptic miniplasmid. J. Bacteriol. 134: $1141-1156$.

Craigie, R. and K. Mizuuchi. 1985. Mechanism of transposition of bacteriophage $\mathrm{Mu}$ : Structure of a transposition intermediate. Cell 41: 867-876.

- 1986. Role of DNA topology in Mu transposition: Mechanism of sensing the relative orientation of two DNA segments. Cell 45: 793-800.

Craigie, R., D.J. Arndt-Jovin, and K. Mizuuchi. 1985. A defined system for the DNA strand-transfer reaction at the initiation of bacteriophage $\mathrm{Mu}$ transposition: Protein and DNA substrate requirements. Proc. Natl. Acad. Sci. 82: 75707574.

Craigie, R., M. Mizuuchi, and K. Mizuuchi. 1984. Site-specific recognition of the bacteriophage $\mathrm{Mu}$ ends by the $\mathrm{Mu} \mathrm{A}$ protein. Cell 39: 387-394.

Ely, B. 1982. Transposition of $\operatorname{Tn} 7$ occurs at a single site on the Caulobacter crescentus chromosome. I. Bacteriol. 151: $1056-1058$.

Fling, M.E. and C. Richards. 1983. The nucleotide sequence of the trimethoprim-resistant dihydrofolate reductase gene harbored by Tn7. Nucleic Acids Res. 11: 5147-5158.

Fling, M.E., J. Kopf, and C. Richards. 1985. Nucleotide sequence of the transposon $\operatorname{Tn} 7$ gene encoding an aminoglycosidemodifying enzyme, $3^{\prime \prime}(9)-O$-nucleotidyltransferase. Nucleic Acids Res. 13: 7095-7106.

Frey, J. and H.M. Frisch. 1985. $\Omega$ mutagenesis in Gram-negative bacteria: A selectable interposon which is strongly polar in a wide range of bacterial species. Gene 36: 143-150.

Furth, M.E. and S.H. Wickner. 1983. Lambda DNA replication. In Lambda II led. R.W. Hendrix, J.W. Roberts, F.W. Stahl, and R.A. Weisberg), pp. 145-173. Cold Spring Harbor Laboratory, Cold Spring Harbor, New York.

Gay, N.J., V.L.J. Tybulewicz,, and J.E. Walker. 1986. Insertion of transposon $\mathrm{Tn} 7$ into the Escherichia coli $g \operatorname{lm} S$ transcriptional terminator. Biochem. J. 234: 111-117.

Grindley, N.D.F. and R.R. Reed. 1985. Transpositional recombination in prokaryotes. Annu. Rev. Biochem. 54: 863-896.

Grindley, N.D.F. and D.J. Sherratt. 1978. Sequence analysis at IS1 insertion sites: Models for transposition. Cold Spring Harbor Symp. Quant. Biol. 43: 1257-1261.

Hauer, B. and J.A. Shapiro. 1984. Control of Tn7 transposition. Mol. Gen. Genet. 194: 149-158.

Hernalsteens, J.-P., F. Van Vliet, M. De Beuckeleer, A. Depicker, G. Engler, M. Lemmers, M. Holsters, M. Van Montagu, and J. Schell. 1980. The Agrobacterium tumefaciens Ti plasmid as a host vector system for introducing foreign DNA in plant cells. Nature 287: 654-656.

Isberg, R.S. and M. Syvanen. 1981. Replicon fusions promoted by the inverted repeats of Tn5. J. Mol. Biol. 150: 15-32.

Johnson, R.C. and W.S. Reznikoff. 1984. Copy number control of Tn5 transposition. Genetics 107: 9-18.

Kamp, D. and R. Kahmann. 1981. Two pathways in bacteriophage Mu transposition? Cold Spring Harbor Symp. Quant. Biol. 45: 329-336.

Kleckner, N. 1981. Transposable elements in prokaryotes. Annu. Rev. Genet. 15: 341-404.

Lichtenstein, C. and S. Brenner. 1981. Site-specific properties of Tn7 transposition into the E. coli chromosome. Mol. Gen. Genet. 183: 380-387.

- 1982. Unique insertion site of $\operatorname{Tn} 7$ in the E. coli chromosome. Nature 297: 601-603.

Maniatis, T., E.F. Fritsch, and J. Sambrook. 1982. Molecular cloning: A laboratory manual. Cold Spring Harbor Laboratory, Cold Spring Harbor, New York.

McKown, R.L., K.A. Orle, T. Chen, and N.L. Craig. 1988. Nucleotide sequence requirements of Escherichia coli att $T n 7$, a specific site of transposon $\mathrm{Tn} 7$ insertion. $J$. Bacteriol. 170: 352-358.

McKown, R.L., C.S. Waddell, L.K. Arciszewska, and N.L. Craig. 1987. Identification of a transposon Tn7-dependent DNAbinding activity that recognizes the ends of Tn7. Proc. Natl. Acad. Sci. 84: 7807-7811.

Miller, J.H. 1972. Experiments in molecular genetics. Cold Spring Harbor Laboratory, Cold Spring Harbor, New York.

Mizuuchi, K. 1983. In vitro transposition of bacteriophage $\mathrm{Mu}$ : A biochemical approach to a novel replication reaction. Cell 35: $785-794$.

Morisato, D. and N. Kleckner. 1987. Tn10 transposition and circle formation in vitro. Cell 51: 101-111.

Morisato, D., J.C. Way, H.-J. Kim, and N. Kleckner. 1983. Tn10 transposase acts preferentially on nearby transposon ends in vivo. Cell 32: 799-807.

Ouartsi, A., D. Borowski, and J. Brevet. 1985. Genetic analysis of Tn7 transposition. Mol. Gen. Genet. 198: 221-227.

Prentki, P. and H.M. Krisch. 1984. In vitro insertional mutagenesis with a selectable DNA fragment. Gene 29: 303-313.

Raibaud, O., M. Roa, C. Braun-Breton, and M. Schwartz. 1979. Structure of the malB region in Escherichia coli K12. I. Genetic map of the malk-lamB operon. Mol. Gen. Genet. 174: $241-248$.

Rogers, M., N. Ekaterinaki, E. Nimmo, and D. Sherratt. 1986. Analysis of Tn7 transposition. Mol. Gen. Genet. 205: 550556.

Shapiro, J.A. 1979. Molecular model for the transposition and replication of bacteriophage $\mathrm{Mu}$ and other transposable elements. Proc. Natl. Acad. Sci. 76: 1933-1937.

- (ed.) 1983. Mobile genetic elements. Academic Press, Orlando.

Smith, G.M. and P. Jones. 1984. Effects of deletions in transposon $\operatorname{Tn} 7$ on its frequency of transposition. I. Bacteriol. 157: 962-964.

- 1986. Tn7 transposition: A multigene process. Identification of a regulatory gene product. Nucleci Acids Res. 14: 7915-7927.

Struhl, K. 1983. Direct selection for gene replacement events in yeast. Gene 26: 231-242.

Thomson, J.A., M. Hendson, and R.M. Magnes. 1981. Mutagenesis by insertion of drug resistance transposon $\mathrm{Tn} 7$ into a Vibrio species. I. Bacteriol. 148: 374-378.

Walker, J.E., N.J. Gay, M. Saraste, and A.N. Eberle. 1984. DNA sequence around the Escherichia coli unc operon. Biochem. J. 224: 799-815.

Wishart, W.L., J.R. Broach, and E. Ohtsubo. 1985. ATP-dependent specific binding of $\operatorname{Tn} 3$ transposase to $\operatorname{Tn} 3$ inverted re- 
peats. Nature 314: 556-558.

Zerbib, D., M. Jakowec, P. Prentki, D.J. Galas, and M. Chandler. 1987. Expression of proteins essential for IS1 transposition: Specific binding of InsA to the ends of ISI. EMBO $I$. 6: 3163-3169. 


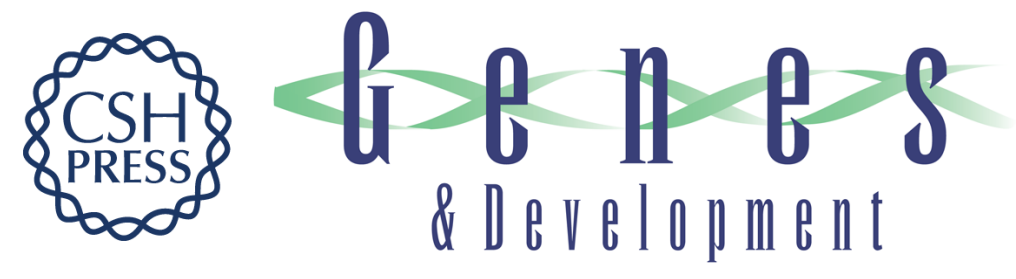

\section{Tn7 transposition: two transposition pathways directed by five Tn7-encoded genes.}

C S Waddell and N L Craig

Genes Dev. 1988, 2:

Access the most recent version at doi:10.1101/gad.2.2.137

$\begin{array}{ll}\text { References } & \text { This article cites } 44 \text { articles, } 15 \text { of which can be accessed free at: } \\ \text { http://genesdev.cshlp.org/content/2/2/137.full.html\#ref-list-1 }\end{array}$

License

Email Alerting Receive free email alerts when new articles cite this article - sign up in the box at the top Service right corner of the article or click here.

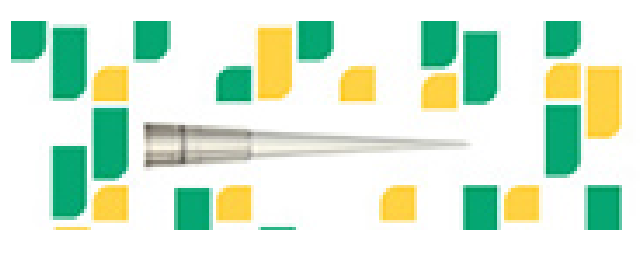

Focused on your science. 